DISTRIBUTION STATEMENT A. Approved for public release; distribution is unlimited.

\title{
Continental Shelf Embayments of the Eastern Margin of the Philippines; Lamon Bay Stratification \& Circulation
}

\author{
Arnold L. Gordon \\ Lamont-Doherty Earth Observatory \\ 61 Route 9W \\ Palisades, NY 10964-8000 \\ tele: (845) 365-8325 \\ fax: (845) 365-8157 \\ agordon@ldeo.columbia.edu
}

Award Number: N00014-13-1-0275

\section{LONG-TERM GOALS}

To investigate the circulation, stratification and the Shelf-Slope interaction within Lamon Bay of the eastern margin of the Philippines, marking the 'birth' of the Kuroshio, before its encounter with Luzon Strait.

\section{OBJECTIVES}

The objectives of the Lamon Bay program are to quantity the spatial and temporal characteristics of the ocean processes governing the stratification \& circulation within Lamon Bay, including shelf / slope exchange, and their relationship to regional marine ecosystems, as well as to investigate linkage of Lamon Bay oceanography to the larger scale, such as the development of the Kuroshio. The objectives are attained utilizing the observations obtained during the R/V Revelle in May/June 2011 and April/May 2012 research cruises; time series from moorings spanning the cruises; as well as satellite derived data and other observations collected as part of the OKMC program,

\section{APPROACH}

The Lamon Bay observational program of 2011-12, provides significant insights into the workings of the embayment environment of the eastern coast of Luzon, the Philippines. The proposed data analysis fall under 3 categories:

1. Circulation \& stratification and physical processes within Lamon Bay;

2. Linking the physical processes to the marine ecosystems of Lamon Bay, in collaboration with Philippine colleagues: water column oxygen profile; satellite ocean color regional time series coupled to ship based observations of CTD Fluorometer LSS and Transmissometer and Plankton Sampling.

3. Relating Lamon Bay oceanography to the larger regional scale, including the relationship to the NEC Bifurcation and Kuroshio generation and characteristics of the flow into Luzon Strait and of the Indonesian throughflow. 


\section{Report Documentation Page}

Form Approved

OMB No. 0704-0188

Public reporting burden for the collection of information is estimated to average 1 hour per response, including the time for reviewing instructions, searching existing data sources, gathering and maintaining the data needed, and completing and reviewing the collection of information. Send comments regarding this burden estimate or any other aspect of this collection of information,

including suggestions for reducing this burden, to Washington Headquarters Services, Directorate for Information Operations and Reports, 1215 Jefferson Davis Highway, Suite 1204, Arlington

VA 22202-4302. Respondents should be aware that notwithstanding any other provision of law, no person shall be subject to a penalty for failing to comply with a collection of information if it

does not display a currently valid OMB control number.

1. REPORT DATE

30 SEP 2014

4. TITLE AND SUBTITLE

Continental Shelf Embayments of the Eastern Margin of the Philippines; Lamon Bay Stratification \& Circulation

6. AUTHOR(S)

7. PERFORMING ORGANIZATION NAME(S) AND ADDRESS(ES)

Lamont-Doherty Earth Observatory,61 Route

9W,Palisades,NY,10964-8000

9. SPONSORING/MONITORING AGENCY NAME(S) AND ADDRESS(ES)

12. DISTRIBUTION/AVAILABILITY STATEMENT

Approved for public release; distribution unlimited

13. SUPPLEMENTARY NOTES

14. ABSTRACT

15. SUBJECT TERMS

16. SECURITY CLASSIFICATION OF:

a. REPORT

unclassified b. ABSTRACT

unclassified c. THIS PAGE

unclassified
17. LIMITATION OF ABSTRACT

Same as

Report (SAR)
3. DATES COVERED

00-00-2014 to 00-00-2014

5a. CONTRACT NUMBER

5b. GRANT NUMBER

5c. PROGRAM ELEMENT NUMBER

5d. PROJECT NUMBER

5e. TASK NUMBER

5f. WORK UNIT NUMBER

8. PERFORMING ORGANIZATION REPORT NUMBER

10. SPONSOR/MONITOR'S ACRONYM(S)

11. SPONSOR/MONITOR'S REPORT NUMBER(S) 
The research is carried out with Pierre Flament of the University of Hawaii, and the Philippine research team; Lamon Bay program is a component of the OKMC DRI.

\section{WORK COMPLETED}

Background: Reports of Lamon Bay cruise 1 (LB01, May/June 2011) and Lamon Bay cruise 2 (LB02, April/May 2012) provide an overview of the observations and basic insights to Lamon Bay oceanography and its place in the larger scale regional ocean. The reports are available at:

Lamon Bay 1 Report: http://www.ldeo.columbia.edu/ agordon/Reports/LamonBay2011_Report.pdf Lamon Bay 2 Report: http://www.ldeo.columbia.edu/ agordon/Reports/LamonBay2_rept.pdf

The research objectives of the 2011-2012 Lamon Bay observational program (Figure 1) was to quantity the spatial and temporal characteristics of the ocean processes governing the stratification \& circulation within Lamon Bay and their relationship to marine productivity and ecosystems and to investigate possible linkage of Lamon Bay dynamics to the development of the Kuroshio.

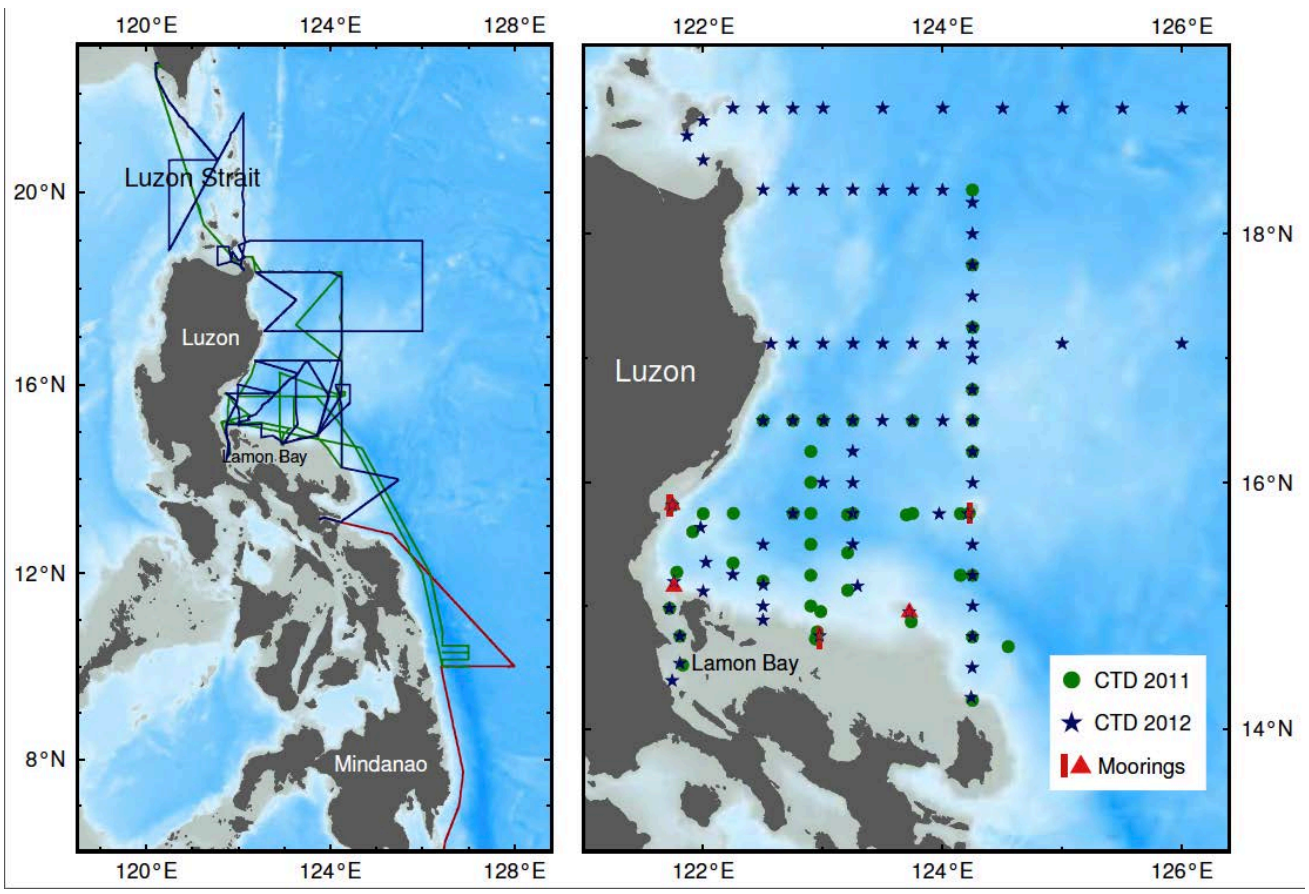

Figure 1: Ship track (left panel) and the sites of CTD stations and moorings (right panel) within Lamon Bay. The ship-based observations were from the R/V Revelle in 18 May- 4 June 2011 (blue ship track) and 24 April - 13 May 2012 (green track). The 2011 CTD stations are shown as blue stars for the 2011 cruise, and as green discs for the 2012 cruise. The mooring sites are shown by red symbols. The red bars are moorings with instrumentation attached to a cable (3 such moorings); the red triangles are instruments at the sea floor within Trawl Resistant Bottom Mooring installation.

Publication 2014: Gordon, A.L., Flament, P., Villanoy, C., Centurioni, L., (2014) “The Nascent Kuroshio of Lamon Bay”, Journal of Geophysical Research-Oceans vol(119) doi:

10.1002/2014JC009882 [also presented at the AGU Ocean Sciences meeting in Honolulu, February 2014] 
Abstract: A northward flowing current, emanating from the North Equatorial Current (NEC) bifurcation at the Philippine margin, enters Lamon Bay along Luzon's eastern coast. There the NEC tropical water masses merge with subtropical water of the western North Pacific to form the Kuroshio. A northward flowing western boundary current is first observed near 16.5_N, marking the initiation of the Kuroshio. The current feeding into the nascent Kuroshio of Lamon Bay is bracketed by an anticyclonic dipole to its northeast and a cyclonic dipole to its southwest. Ship-based observational programs in the spring seasons of 2011 and 2012 detect a shift of the Lamon Bay thermohaline stratification with marked enrichment of NEC tropical thermocline water in 2012 relative to a dominant western North Pacific subtropical stratification of 2011. Temperature-salinity time series from moorings spanning the two ship-based observations identify the timing of the transition as December 2011. The NEC bifurcation was further south in May 2012 than in May 2011. We suggest that the more southern bifurcation in May 2012 induced increased NEC thermocline water injection into Lamon Bay and nascent Kuroshio, increasing the linkage of the western North Pacific subtropical and tropical thermoclines. This connection was reduced in May 2011 as the NEC bifurcation shifted into a more northerly position and western North Pacific subtropical thermocline dominated Lamon Bay stratification.

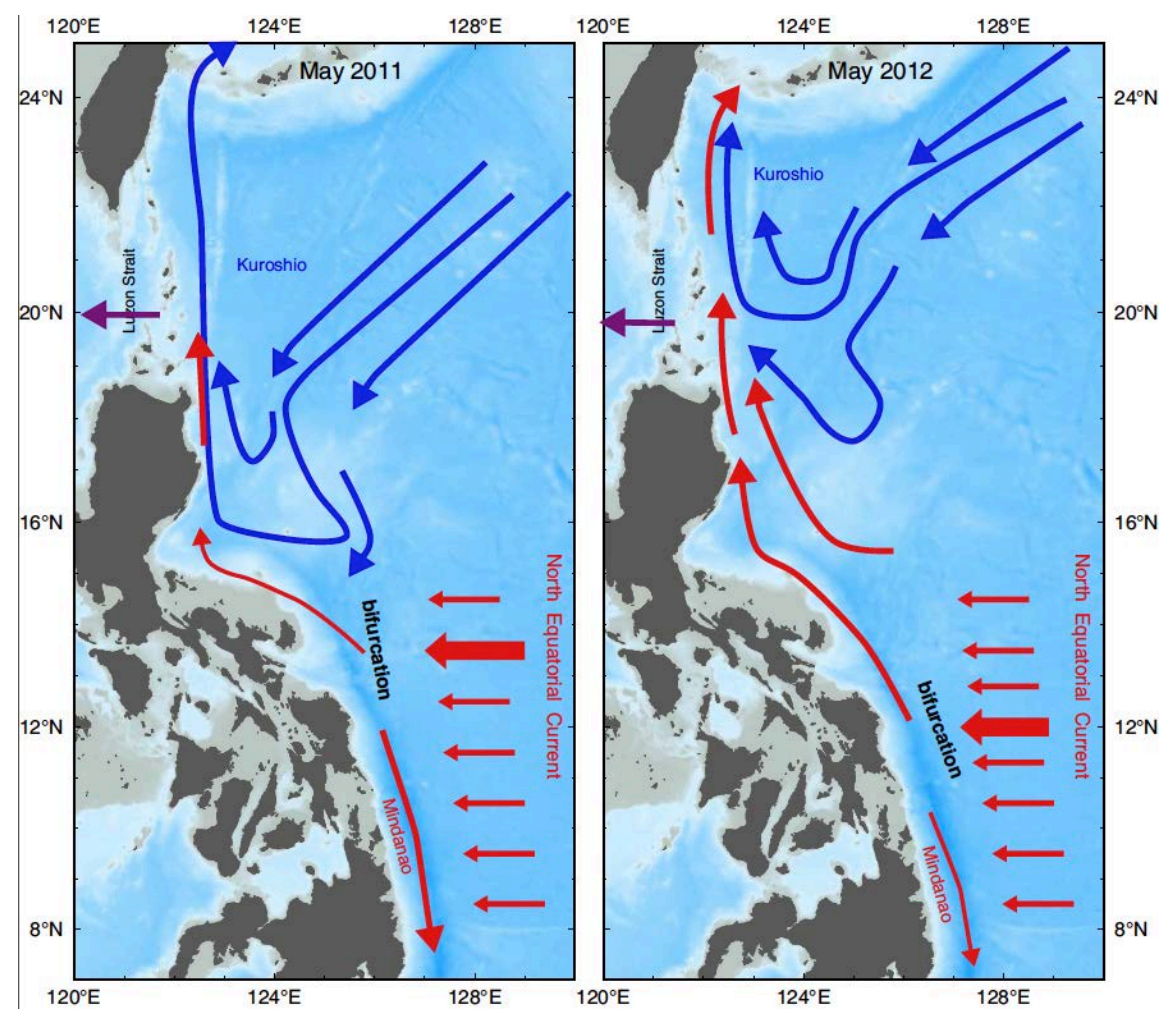

Figure 2. [figure 11 within publication]. Schematic of the circulation pattern based on the water mass stratification observed by two Lamon Bay research cruises, May/June 2011 and April/May 2012. In 2011 the subtropical thermocline stratification dominated Lamon Bay, whereas in 2012 that regime retreaded northward, replaces by the tropical stratification of the North Equatorial Current (NEC). The NEC Bifurcation shifted latitude between the two cruises: more southern position in 2012 
Submitted to Journal of Geophysical Research - Atmosphere, September 2014: Julie Pullen, Arnold L. Gordon, Maria Flatau and James D. Doyle, Cesar Villanoy, "Multi-scale influences on extreme winter rainfall in the Philippines"

Abstract: During 2007-2008 the Philippines experienced the greatest rainfall in 40 winters. We use a combination of observations (including 48 meteorological stations distributed throughout the islands, TRMM satellite-sensed precipitation, and shipboard measurements) along with a high-resolution twoway coupled ocean/atmosphere model (3 km COAMPS $\left.{ }^{\circledR}\right)$ to examine this anomalous season. As expected from climatology, rainfall was greatest on the eastern side of the archipelago, with seasonal totals exceeding $4000 \mathrm{~mm}$ in some locations. A moderate to strong La Nina increased the rainfall across the region. But discrete precipitation events delivered the bulk of the rain to the area, and coincided with intense MJO activity over the archipelago and a late February cold surge. General patterns and magnitudes of rainfall produced by the two-way coupled model agreed with observations from land and from space. During the discrete events, the 3-km COAMPS also produced high amounts of precipitation in the mountainous parts of central Philippines. Direct observations were limited in this region. However the government reported river flooding and evacuations in Mindoro during February 2008 as a result of significant rainfall. In addition, shipboard measurements from late January 2008 (collected by the Philippines Straits Dynamics Experiment) reveal a fresh lens of water to the west of the island of Mindoro, consistent with high freshwater discharge (river run-off) into the coastal area.

Submitted to Deep-Sea Res. Matet L. Escobar, Maria Lourdes San Diego-McGlone, Cesar S. Villanoy, Olivia C. Cabrera, Fernando P. Siringan, Ronald Lloren, Gil S. Jacinto and Arnold L. Gordon, "Dissolved oxygen variability of thermocline waters off Eastern Luzon, Philippines during the last millennium"

Abstract: Dissolved Oxygen (DO) profiles in waters of Lamon Bay off Eastern Luzon for 2011 (neutral ENSO) and 2012 (La Niña) showed a shift in DO concentration within the thermocline. Based on optimum multiparameter analysis, waters of Lamon Bay come mainly from the Kuroshio Recirculation gyre during neutral ENSO conditions, whereas during La Niña event there is a marked increase of North Pacific Tropical Waters, with lower DO, derived from the North Equatorial Current. Variability in DO within Lamon Bay is driven by the change in water mass brought about by an ENSO-influenced shift in the bifurcation latitude. To study the variability of dissolved oxygen on a longer timescale, geochemical proxies found in marine sediments were utilized. A sediment core taken from a deep basin within Lamon Bay was used to reconstruct the paleodepositional redox environment in waters off Eastern Luzon. The geochemical proxies V and Mn showed DO fluctuations in the past 1000 years. Two dominant periodicities ( 8-16 years and $\sim 32-64$ years) seen in the wavelet analysis were associated with the Pacific Decadal Oscillation.

\section{RESULTS}

Progress of on-going Joint research with the Philippine researchers (Villanoy, Cabrera and Alabia, Marine Science Institute, University of the Philippines):

1. The Lamon Bay Chl-a pattern vary in concert with the water mass stratification patterns as observed on the two Lamon Bay cruises (May 2011 and May 2012, see Gordon et al, 2014). Satellite derived chl-a in Lamon Bay from 1998 through 2013 are related to the NEC bifurcation latitude (using Qiu/Chen 2010, eq 2). The two Lamon Bay cruises and intervening mooring 
timeseries, reflect a longer-term relationship, with likely relevance to the marine ecosystem of Lamon Bay. However, the chl-a pattern is not a linear function of the NEC bifurcation as there are outliers from such a relationship, which are likely due (we think) to differences in the nature of the El Nino events [regular and Modoki types].

2. Sea Surface Height anomaly vs. T/S; two parts:

a: At Benham Bank ( 124.23E; 15.75N; where we had a ADCP and T/S mooring spanning the Lamon Bay cruises), we see, as expected, the temperature at $170 \mathrm{~m}$ (thermocline) relates to the Aviso SSHa; wiggles mainly in 2011 reflect passing ocean eddies at $~ 1.5$ months intervals. But the SSHa to $170 \mathrm{~m}$ temperature relationship is not an exact linear fit, as would be expected if the $\mathrm{T}$ and $\mathrm{S}$ depth profiles do not change, but rather just heaved with passing mesoscale. Stronger [weaker] dT/dz occurs when there is more tropical [subtropical] water with strong s-max at upper thermocline, a response to a southward [northward] shift of the NEC bifurcation. Additionally there is an outlier induced by passing of a October 2011 typhoon, that may have altered the stratification in the upper $\sim 200 \mathrm{~m}$. After Feb 2012 sea level drop relative to temperature at $170 \mathrm{~m}$, as warmer water is linked to salty [s-max] higher density water, injected from the tropics. We are looking to see if there are enough Argo profiles in Lamon Bay to get a longer T/S stratification time series than offered by the two Lamon Bay moorings. Maybe OKMC glider data might be significant.

b: The satellite altimeter time series, since 1993 reveal the changing nature of the westward moving eddies reaching into Lamon Bay; they vary in numbers and latitude, sometimes even missing Luzon by tracking mostly north of $\sim 18.5 \mathrm{~N}$. We are looking into the possibility that they trigger of topographic trapped Kelvin Waves that pass into Lamon Bay that can be picked up by the Lamon Bay moorings. This work expands the eddy and Kuroshio relationship reported by the Ren-Chieh Lien et al 2014 JRG paper.

Cesar Villanoy and Pierre Flament will present Lamon Bay research at OKMC meeting in January 2015.

\section{IMPACT/APPLICATIONS}

The spatial and temporal shelf/slope interactions processes within and at the boundaries of Lamon Bay may be instrumental in the origin and dynamics of the Kuroshio Current including the links of the Kuroshio to the North Pacific subtropical gyre and Pacific North Equatorial Current Bifurcation. The cyclonic dipole circulation of the southwest Lamon Bay is likely closely linked to the active marine ecosystem characteristic, and shelf/slope interaction.

\section{RELATED PROJECTS}

OKMC (Origin of the Kuroshio and Mindanao Current).

\section{HONORS/AWARDS/PRIZES}

Arnold L. Gordon Fellow, Association for the Advancement of American Science, February 2014 